\title{
MULTI-SCALE SEISMIC SIMULATION OF RC BUILDING COUPLED WITH DRYING SHRINKAGE AND STEEL CORROSION
}

\author{
KOICHI MAEKAWA ${ }^{*}$, NOBUHIRO CHIJIWA ${ }^{\dagger}$ \\ The University of Tokyo \\ Tokyo, JAPAN \\ e-mail: maekawa@concrete.t.u-tokyo.ac.jp \\ ${ }^{\dagger}$ Tokyo Institute of Technology \\ Tokyo, Japan \\ e-mail: chijiwa@cv.titech.ac.jp
}

Key words: Drying shrinkage, Seismic Performance, Dynamics, Corrosion, Cracking

\begin{abstract}
The multi-scale thermo-hygral modeling is applied to full-scale RC structural systems under combined long-term ambient and short seismic actions, and experimentally verified in reference to a shaking table test of the real scale RC building. Here, the effect of drying shrinkage on seismic responses of framed buildings is numerically investigated and the coupling with steel bar corrosion is discussed as a complex durability problem. It is concluded that the drying effect of structural concrete has the substantial impact on shear capacity of RC members and the story drift of buildings when thin shear walls play a major role of the seismic resistance, and that the deformational mode may vary according to the corrosion of reinforcement as well.
\end{abstract}

\section{INTRODUCTION}

Drying shrinkage of concrete tends to introduce cracking which causes reduction of structural stiffness. Degradation of the shear capacity of RC lineal members has been also reported with regard to drying and autogenous shrinkage of concrete at rather early ages [1-3]. Here, dispersed shrinkage cracks around surfaces of members may grow and extend to a few localized cracking, which penetrates through the core volume of members.

In 2007, large RC nuclear buildings at Kashiwazaki in Japan were strongly shaken by the near-field earthquake. As the acceleration of the base rocks and on-ground facilities was recorded, the back-check analysis was conducted by using the design formulae. The analysis predicted cracking and displacement which was closer to the limit state of steel yielding. But reality is that almost no cracks were found and that 3D-FE analyses reproduced very realistic responses, which do not exceed elasticity.

On the other hand, it is known that the initial stiffness of normal scale buildings under service-loads is almost smaller than the numerical prediction. One of the reasons is the initially induced cracks. In fact, some shrinkage cracks at the corners of member junctions as well as the surface of thin-walls are frequently seen at the normal use. Here, it should be noted that RC nuclear facilities consist of members of large-thickness more than $2 \mathrm{~m}$ whose mechanistic responses are hardly affected by drying shrinkage.

In this paper, the authors try to investigate the impact of moisture-state dependent shrinkage on the seismic responses in reference to the real-scale shaking table test for the multi-story RC building. 


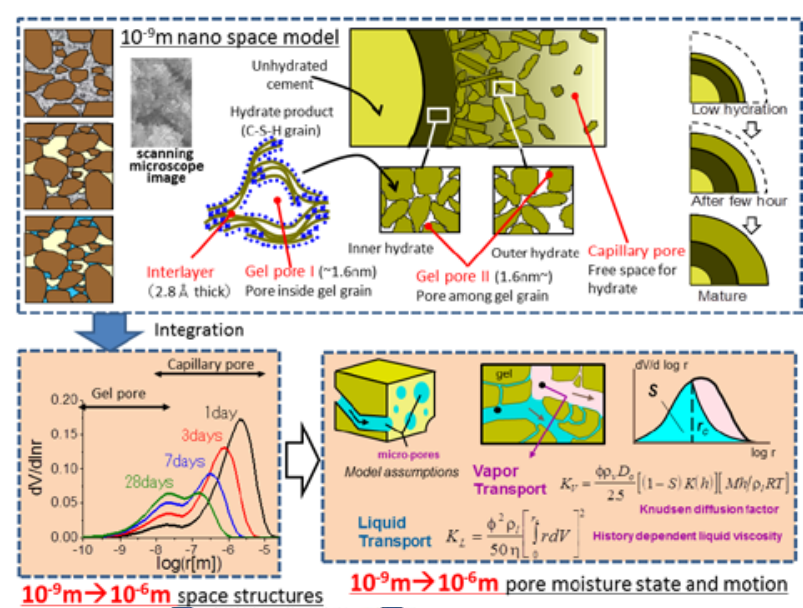

$10^{-9} \mathrm{~m} \rightarrow 10^{-6} \mathrm{~m}$ space structures

$10^{-9} \mathrm{~m} \rightarrow 10^{-6} \mathrm{~m}$ pore moisture state and motion

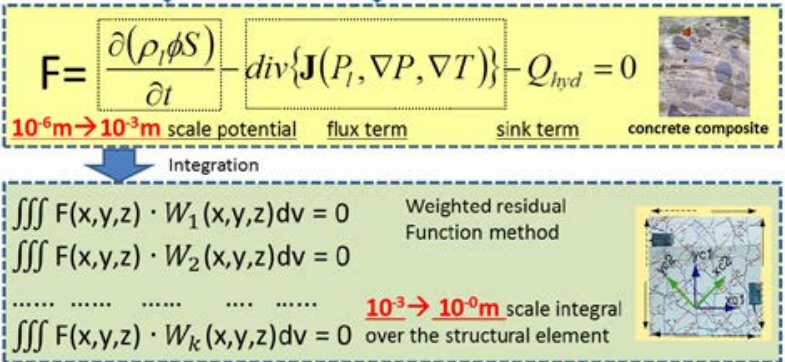
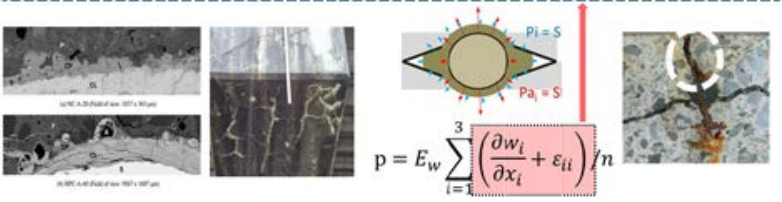

Figure 1: Multi-scale frame for mass conservation and micro-pore structures including moisture.

\section{THERMO-HYGRAL ANALYSIS}

The multi-scale analysis platform [1] was applied to the mixed problem of shear forces and dynamics with shrinkage of concrete as shown in Figure 1 and Figure 2. Cement hydrate's micro-pore structure is statistically expressed with respect to the pore-size distribution, which may vary according to the hydration. The moisture state and its migration are incorporated into the mass balance formula. Here, the diffusivity and the capacity terms in the mass balance equation are computed by volume integral of the thermodynamic equilibrium which develops in micro-pores. For further upscaling of sizes to meter scale, the weight residual function method is applied.

With the same manner, volume-averaged formulation associated with the momentum conservation (mechanical equilibrium) is derived as shown in Figure 2. The meso-scale solidification model is used to bridge the nano-

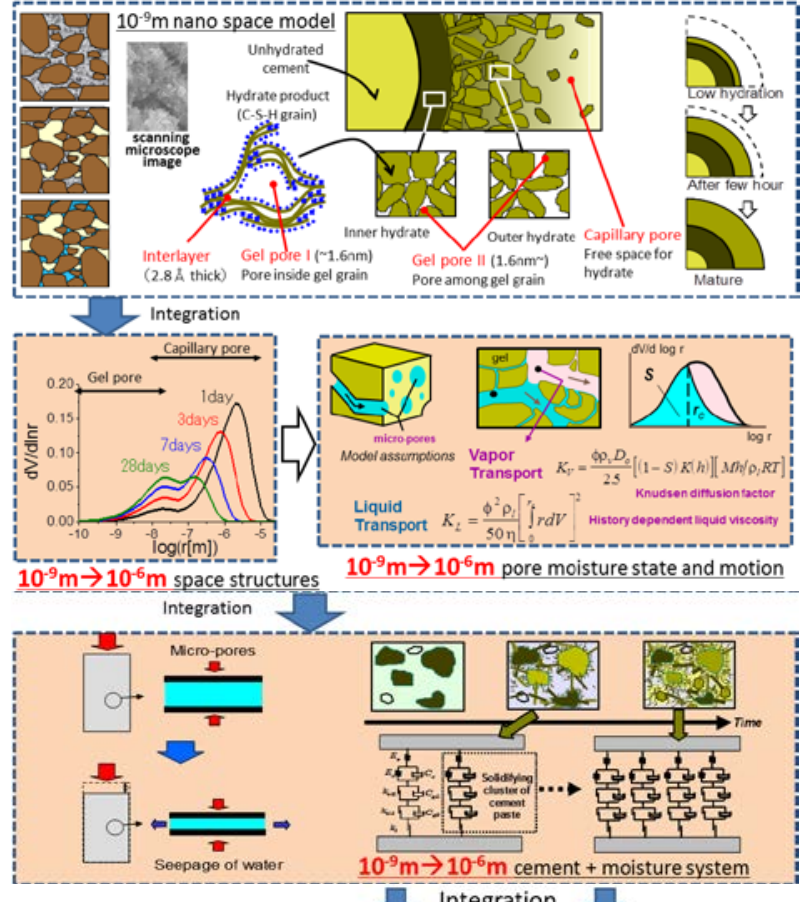

Integration

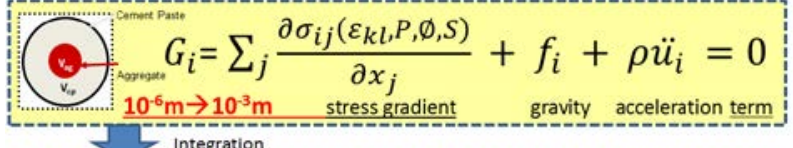

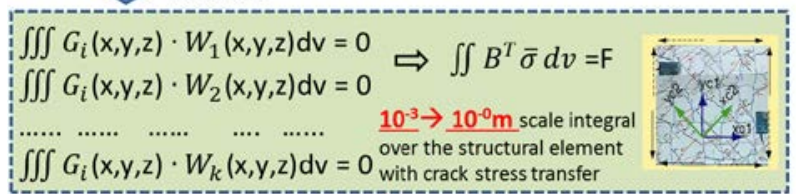

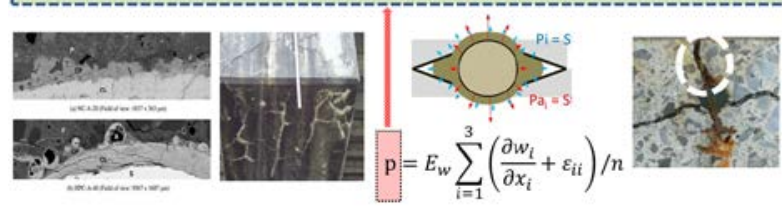

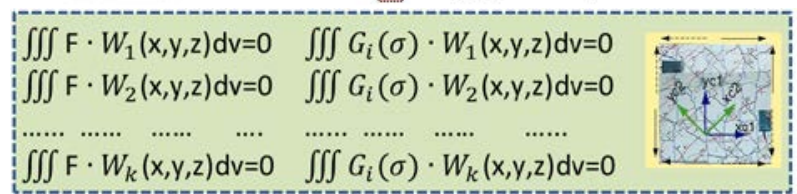

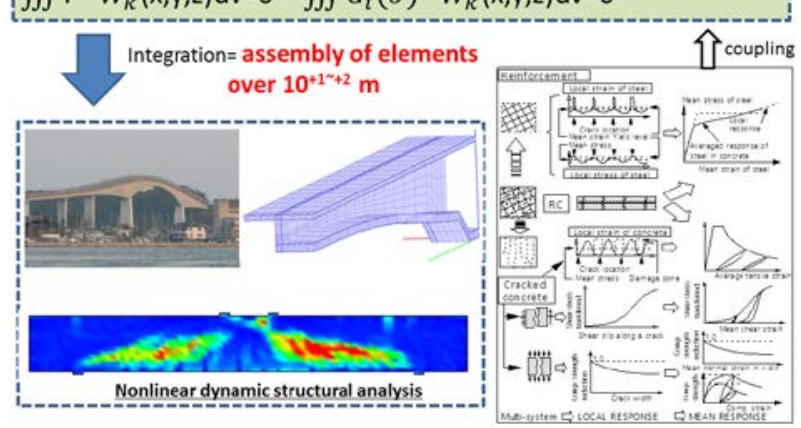

Figure 2: Multi-scale frame for momentum conservation and coupling with thermodynamics events.

scale pores and the meso-level constitutive model [9]. The momentum conservation of meso-scale is scaled up again and coupled with mass conservation as shown in Figure 1. 


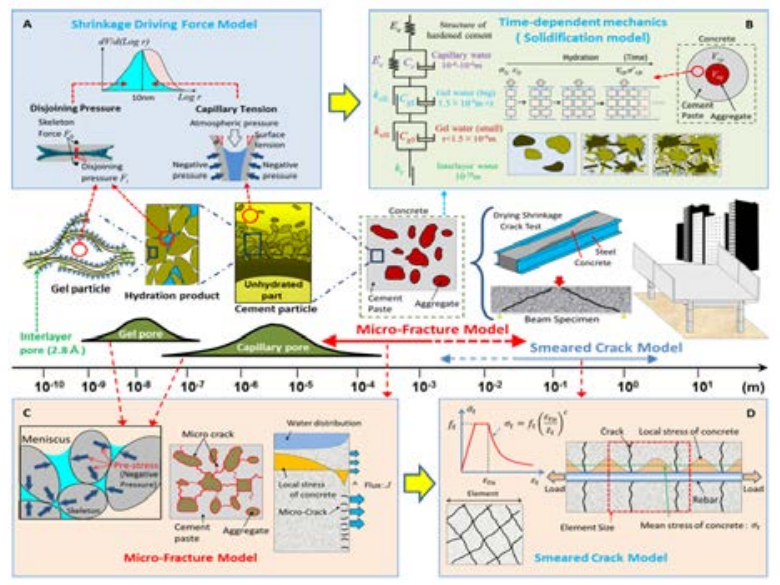

Figure 3: Integrated micro-events and macro-mechanics over the multi-scales.

Finally, the weighted equations over the structural domains are discretized in both space and time on the line of finite-element method. In this study, the chemical events of carbonation, chloride migration and alkaline silica reaction are not mobilized but mere moisture equilibrium and migration in terms of vapor and condensed water is coupled with the cracked concrete solid mechanics as summarized in Figure 3.

\section{VERIFICATION OF MODELING}

The cracked concrete modeling in Figure 3 has been verified under monotonic as well as dynamic states [7]. The authors use the nonorthogonal multi-directional crack interaction model [4, 7] which allows at most six mutually intersecting crack planes inside a finite element domain as shown in Figure 4. The active crack plane, whose crack opening is the largest, normally governs the nonlinearity of multi-intersecting crack assembly. On this plane, the authors apply the tension-softening, compression normal to the crack plane and the shear transfer along the plane.

The softened stress-strain relation of cracked concrete is identified based on the specific fracture energy and the size of the element [7]. The shear slip along crack planes is also calculated so that the local equilibrium is satisfied. These crack modeling is coupled with the concrete composite consisting of aggregates and cement paste, which is also built by the assembly of micro-pores.

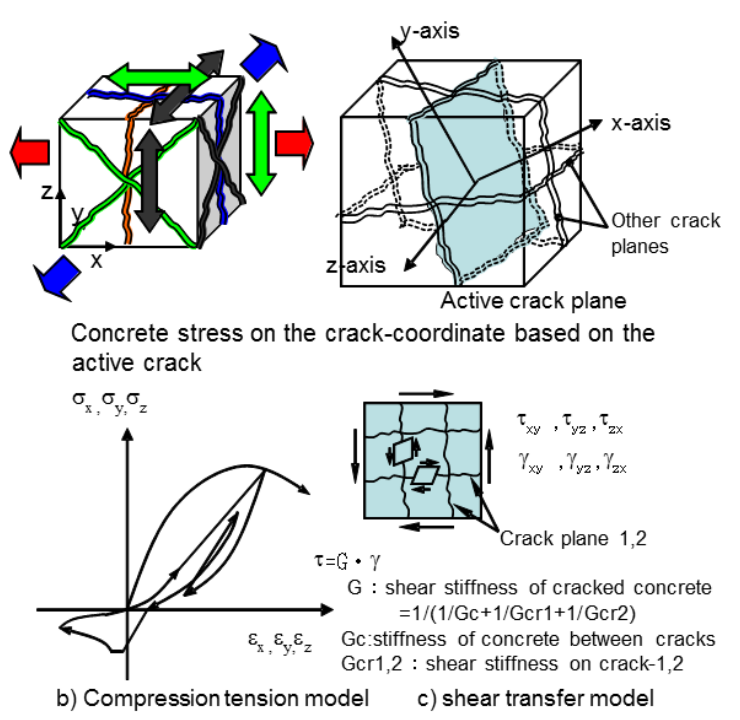

Figure 4: Multi-directional crack plane interaction and stress transfer along the active crack plane.

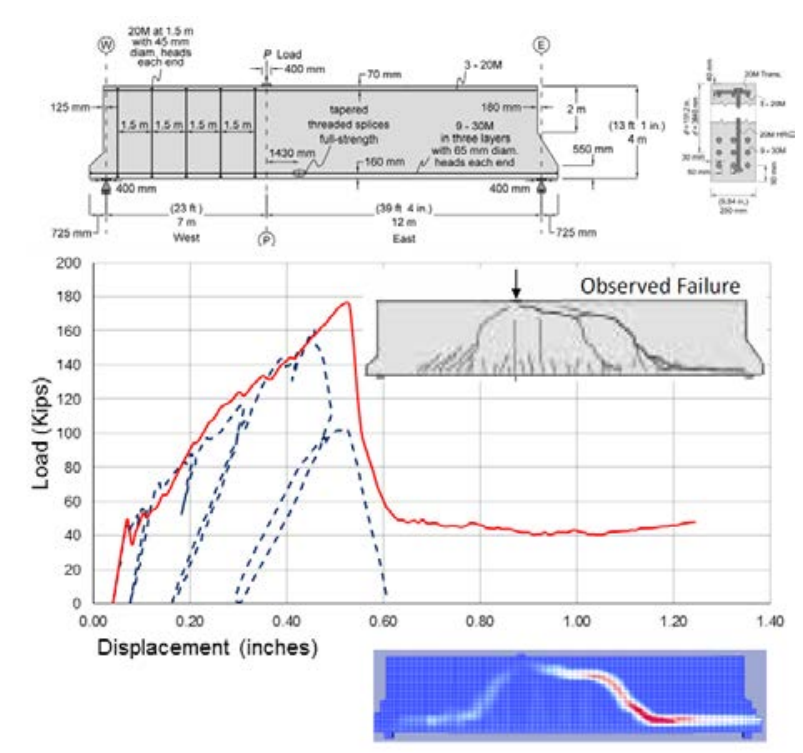

Figure 5: Large-scale RC beam failing in shear: dot line by experiment [5], solid line by analysis.

Figure 5 shows the simulation of the largescale RC beam failing in shear [5]. The experimental result is indicated by a dotted line and the analysis in solid. The nominal shear strength by the analysis is $0.4 \mathrm{MPa}$ and $0.37 \mathrm{MPa}$ calculated from the experiment. If the size is reduced to $10 \%$, the nominal shear strength increases in about $0.8 \mathrm{MPa}$ owing to the size effect of shear failure [6]. The computed results are similar to the one by the empirical formulae. This experimental verification is associated with the macroscopic modeling of crack nonlinearity. 
The effect of drying on the structural behaviors is simulated by simultaneously solving the moisture mass and momentum conservation as indicated in Figure 2 and Figure 3. As the time-dependent constitutive model for cement binder predicts the mesoscale stress in use of the moisture states of micro-pores [1]. Here, concrete creep and shrinkage are inherently considered in association with the moisture states based upon the solidification model [1,9]. The driving force for drying shrinkage is computed based on the capillary pressure drop related to the unsaturated water in capillary pores and the disjoining one rooted in moisture of gel pores. Then, the migration and conservation of moisture in condensed water and vapor are of great importance and the ambient conditions can be handled as the boundary conditions.

The migration of moisture is affected by concrete cracking as well. This coupling of crack mechanics and mass transfer [8] can be obviously taken into account as shown in Figure 6 where the weight loss of the specimen is increased by the forced bending cracks. The crack planes become the short-cut paths of moisture migration. Then, the rate of drying is accelerated by concrete cracking. When the drying rate is accelerated, the risk of additional cracking rises [10].

Figure 7 shows the load-deflection relation of the simply supported RC beam with and without drying [11]. The shear capacity is a little bit reduced in experiment and the similar results are predicted.

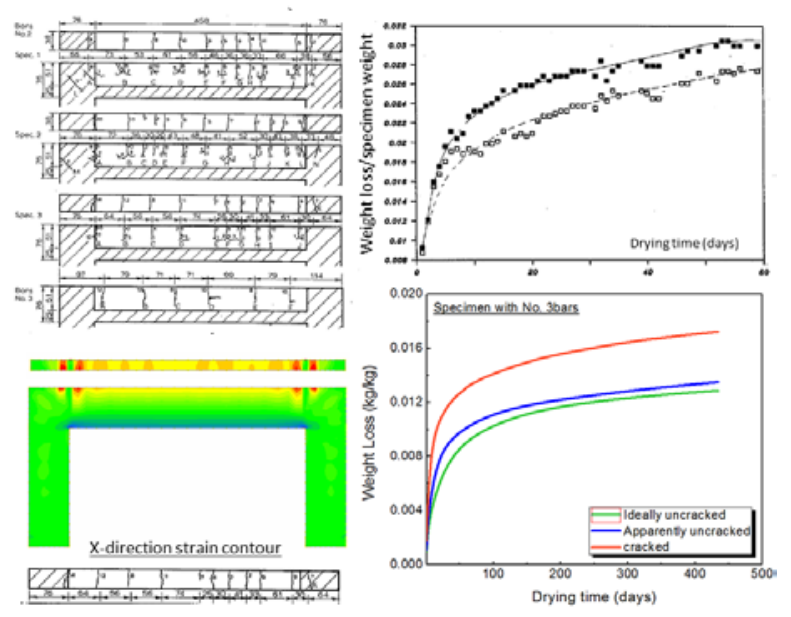

Figure 6: Accelerated drying by cracking.
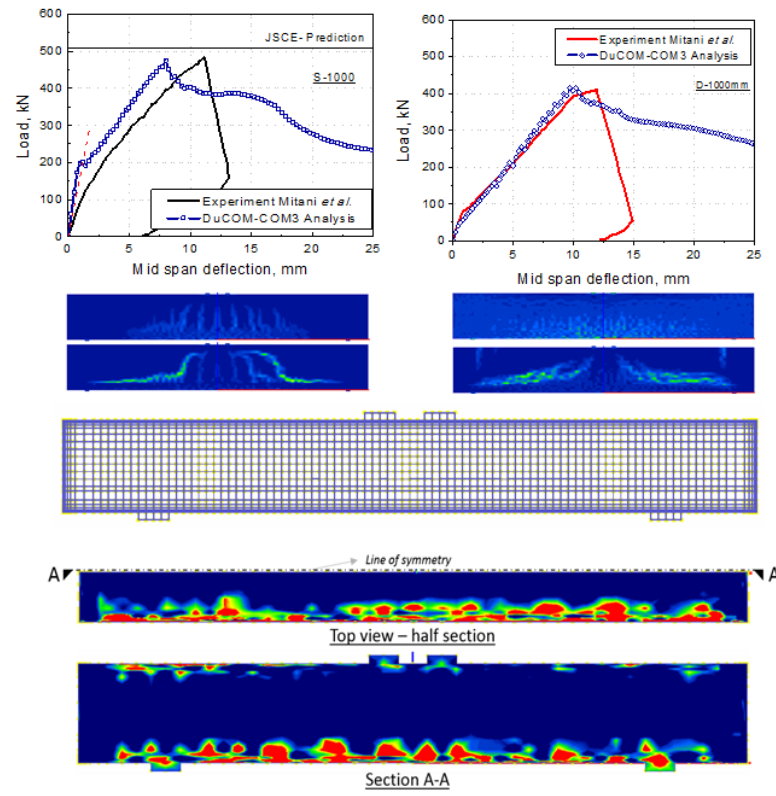

Figure 7: Reduced shear capacity of RC by drying
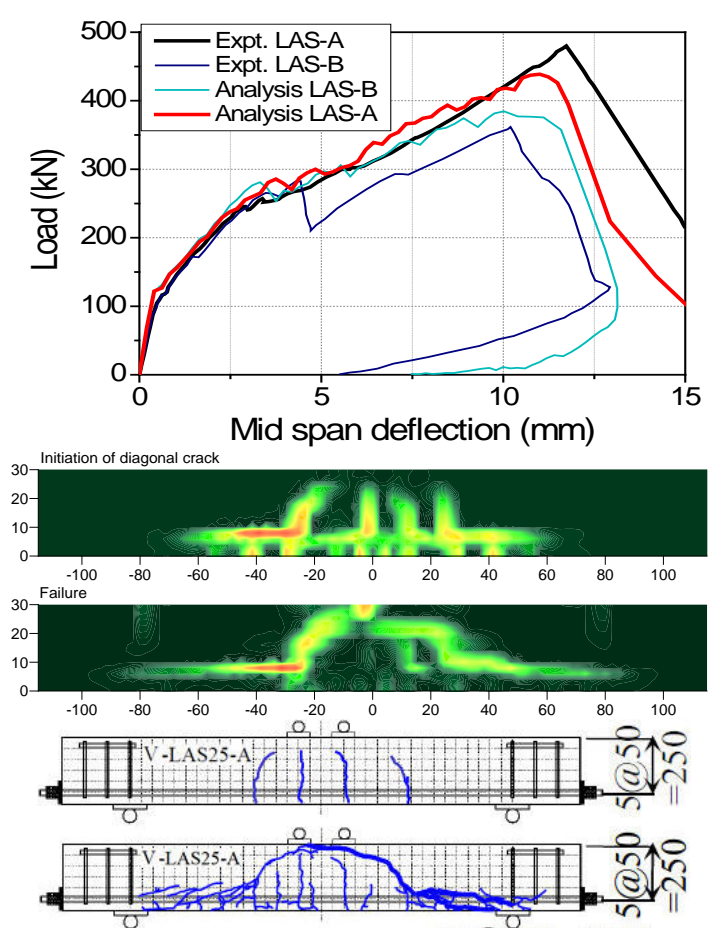

Figure 8: Expansion agent used to compensate autogenous shrinkage for high strength concrete in shear.

When small water to cement ratio is dosed, self-desiccation occurs because of lack of free water accompanied by autogenous shrinkage. This may create the self-equilibrated tensile stress in concrete owing to the confinement of reinforcement. Figures 8 and 9 show the shear capacity of RC beams of high strength concrete in both experiment and multi-scale analyses coupled with moisture motion [12]. 


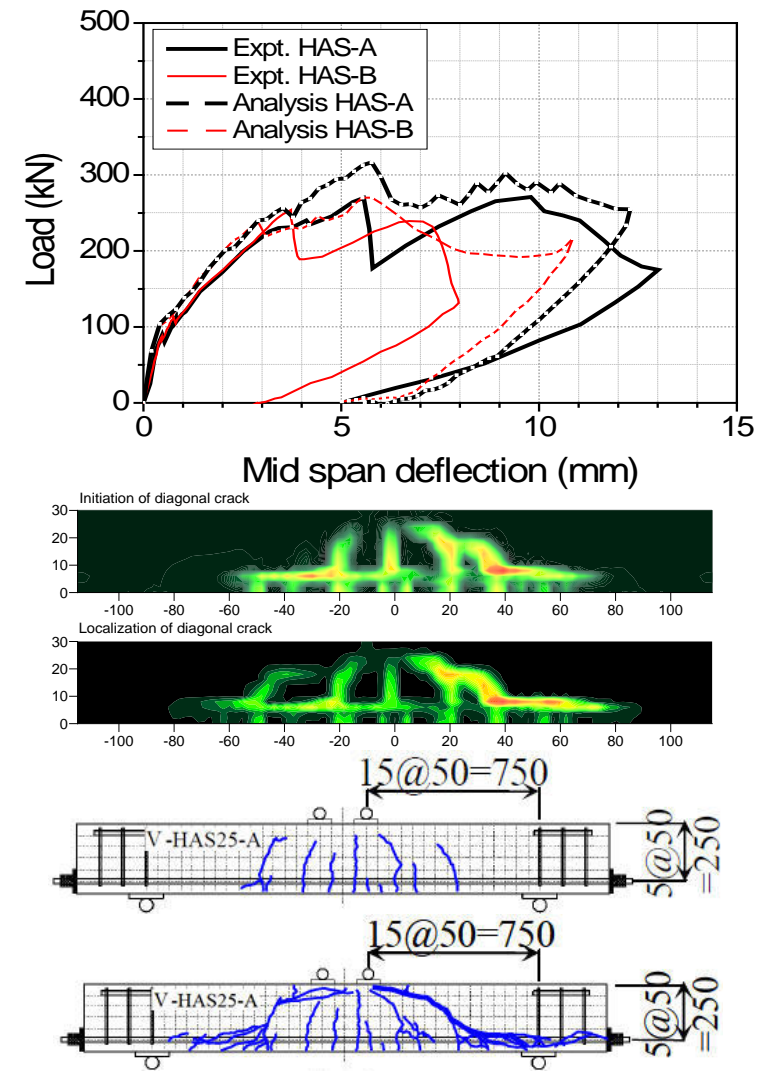

Figure 9: Autogenous shrinkage and shear capacity.

Figure 8 is the referential case of high strength concrete where the expansive agent is used for compensation of the autogenous shrinkage. Since the crack plane of high strength concrete is rather smooth, reduced shear transfer has been taken into account as well as the fracture energy. The simulation of neglected autogenous shrinkage may capture the capacity and the failure mode.

As a comparison to Figure 8, the case without any dosage of expansive agent [12] is shown in Figure 9. The volumetric shrinkage of concrete takes place and the initial stress is induced in both concrete and reinforcement. The shear capacity is substantially reduced in both experiment and analysis. The computed shear crack pattern also matches the experiment.

Since 2000, the nonlinear analysis has been applied to the fatigue life assessment under moving loads [1,14] as shown in Figure 10. There is no critical difference between the seismic analysis (several cycles of load reversal) and the fatigue simulation (millions cycles) in view of the computational scheme.
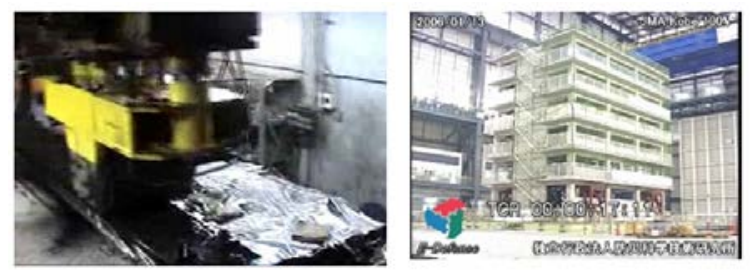

$10^{6}-10^{7}$ cycles, lower stress level $10-20$ cycles, much high strain level (e-defense) single sided, $10-50$ years reversed cyclic, $10-60 \mathrm{sec}$
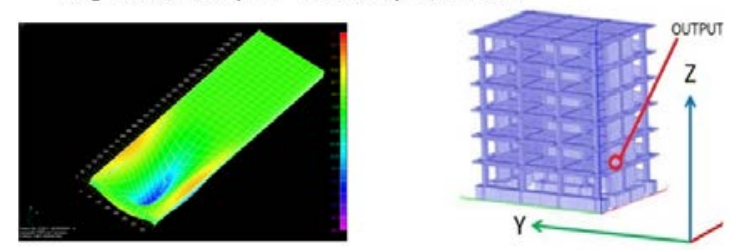

Figure 10: Similarity of RC slab under wheel-type loads and RC building under earthquake.

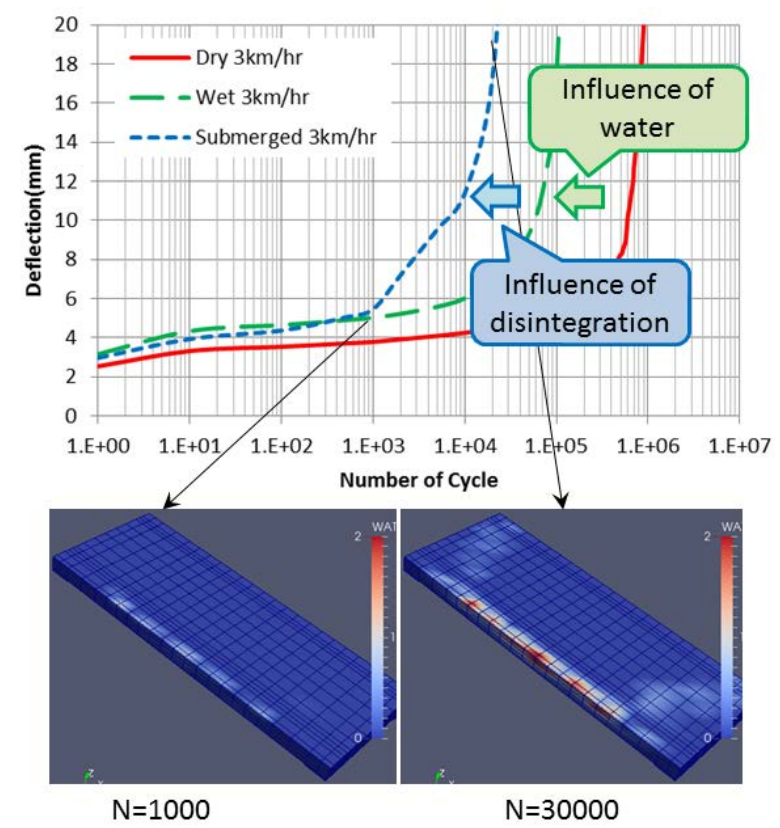

Figure 11: Fatigue life under dry and wet conditions.

Figure 11 indicates the slab deflection in progress under constant but moving loads. The mode of failure is out-of-plane shear. Fatigue life of RC slabs is known to be much shortened compared to the case of fixed point loads [13]. Here, it should be noted that the stagnant water much deteriorates the fatigue life. The cyclic open-closure of cracks causes the pressure of condensed water remaining inside crack gaps. The provoked pressure is transferred to capillary pores, which finally lead to disintegration of cement concrete composites [15]. Both drying and wetting are major factor of the life of RC and the multiscale simulation may capture the behaviors. 


\section{DRYING SHRINKAGE ON SEISMIC PERFORMANCES OF RC BUILDING}

The target RC to investigate the influence of drying shrinkage on the dynamics is the sixstory building [16], which was tested dynamically on the large-scale shaking table at E-Defense, Miki, Japan (See Figure 12).

The multi-scale hygral analysis traces the development of hydration, solidification after placing and the curing processes. The temperature and relative humidity recorded in the experiment are set forth as the ambient boundary conditions. Then, the compressive strength of concrete, which is estimated based upon the developed micro-pore structures, is not the input data for the simulation, but the computed material property.

Figure 13 shows the FE discretization of the whole structure. The shear walls are placed in between beams and columns. Degenerated finite elements like beams, Mindlin plates and shells are not used but full three-dimensional solid finite elements are allocated even though thin wall members are placed, because, mass conservation and migration are discretized on the solid elements of 3D extent.

After wet curing, form stripping is analytically simulated and drying begins. Just before the shaken base of the building targeted, some shrinkage cracking is numerically introduced. As a matter of fact, the cracking was detected practically in the mockup RC building specimen as shown in Figure 14. Thus, the reduction of the initial structural stiffness is inherently treated in the analysis.

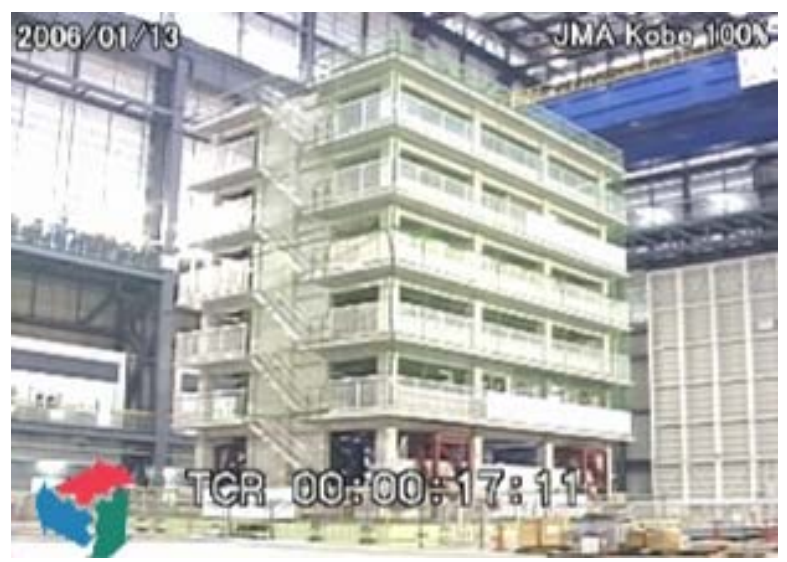

Figure 12: Tested real-scale RC multi-story building.
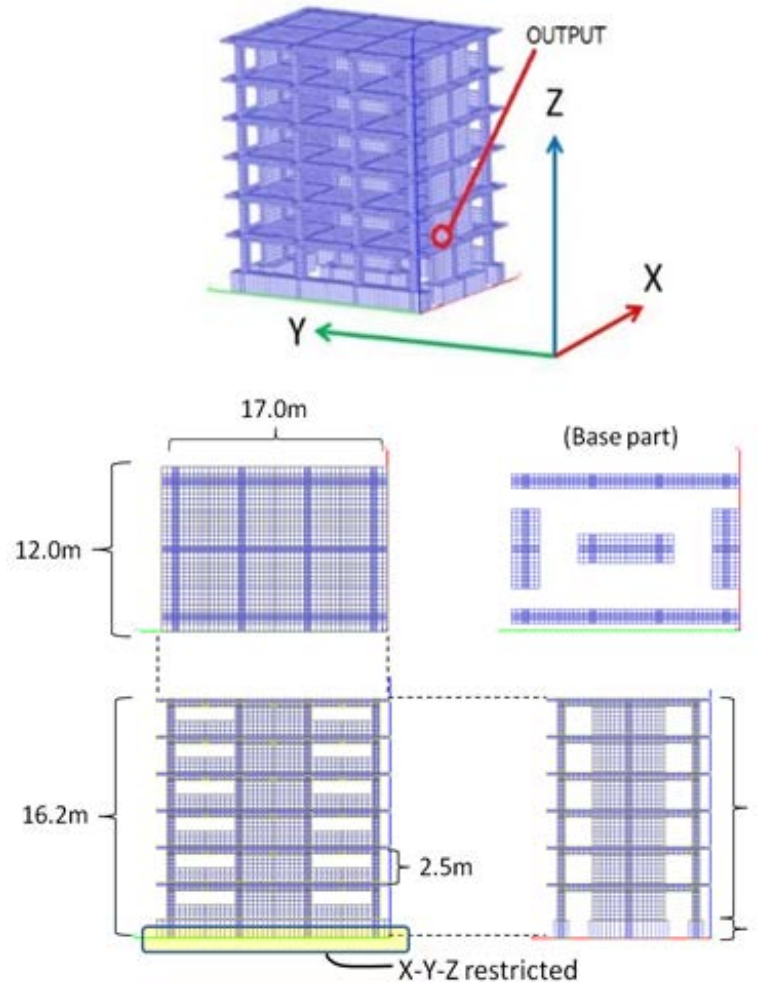

Figure 13: FE discretization for the multi-scale hygralmechanistic analysis.

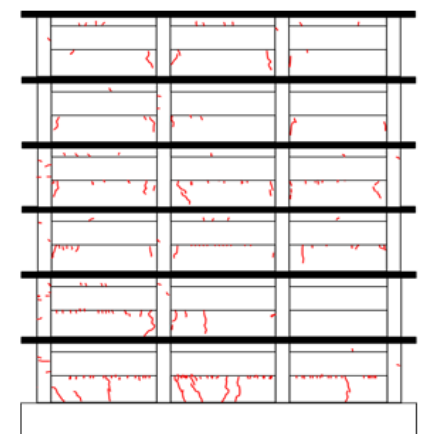

Figure 14: Cracking before the seismic loading.

The dynamic responses of the experiment and the simulation are shown in Figure 15. Applied was the two-way input base acceleration whose magnitude was step-bystep increased in 10, 25, 50 and $100 \%$ of the referential one recorded in 1995 Kobe Great Earthquake. The complex mode of X-Y sway of the second floor is fairly reproduced in the analysis. The Z-directional displacement is associated with the yield of reinforcement. Figure 15 shows the failure modes of the internal columns which are surrounded by spandrel walls and fail with diagonal shear cracks. The simulation certainly captures them. 

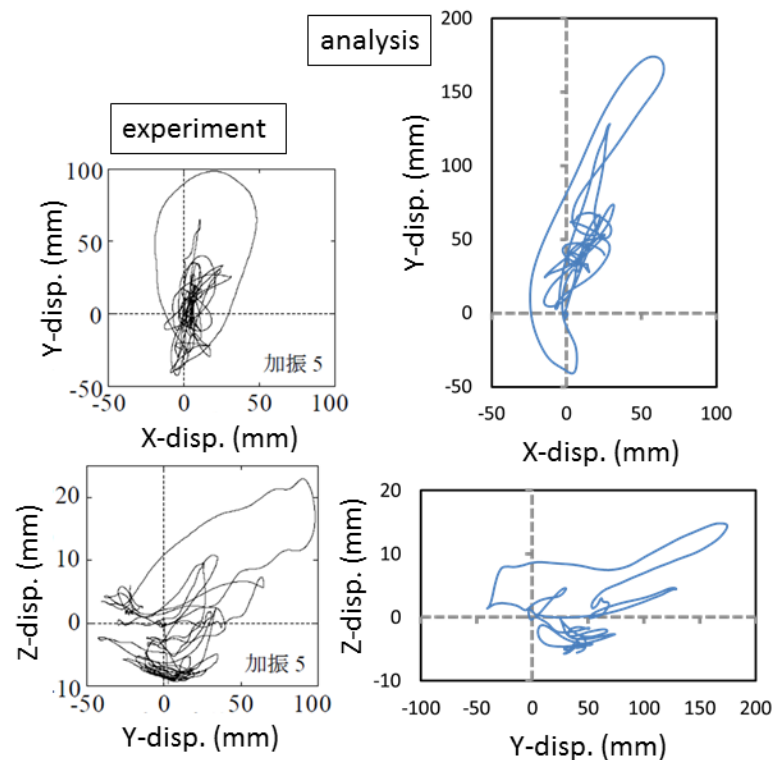

Figure 15: Computed displacement responses in 3-way directions - experiment and analysis -.

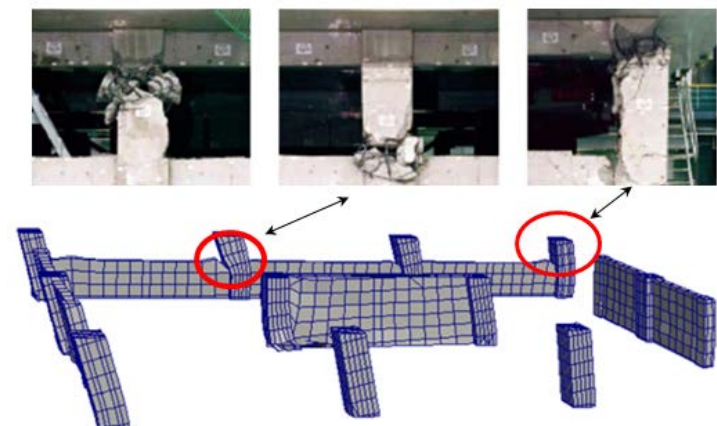

Figure 16: Failure mode of the columns attached to the spandrel walls.

In order to quantitatively verify the impact of drying shrinkage of concrete on the seismic responses, the complete sealed curing is numerically assumed by not allowing the flux exchange of moisture through the surface boundaries of the structure.

Figure 17 indicates the displacement responses of the perfectly sealed case in the thermos-dynamical viewpoint. Under the small and middle levels of input ground acceleration, the $X-Y$ sway is greatly controlled. As the initial structural stiffness is reduced by drying shrinkage cracking just after the load action, it is reasonable to have a difference according to the curing conditions. An interesting point is that the effect of drying extends to highly inelastic responses of the structures under great motion of the ground.
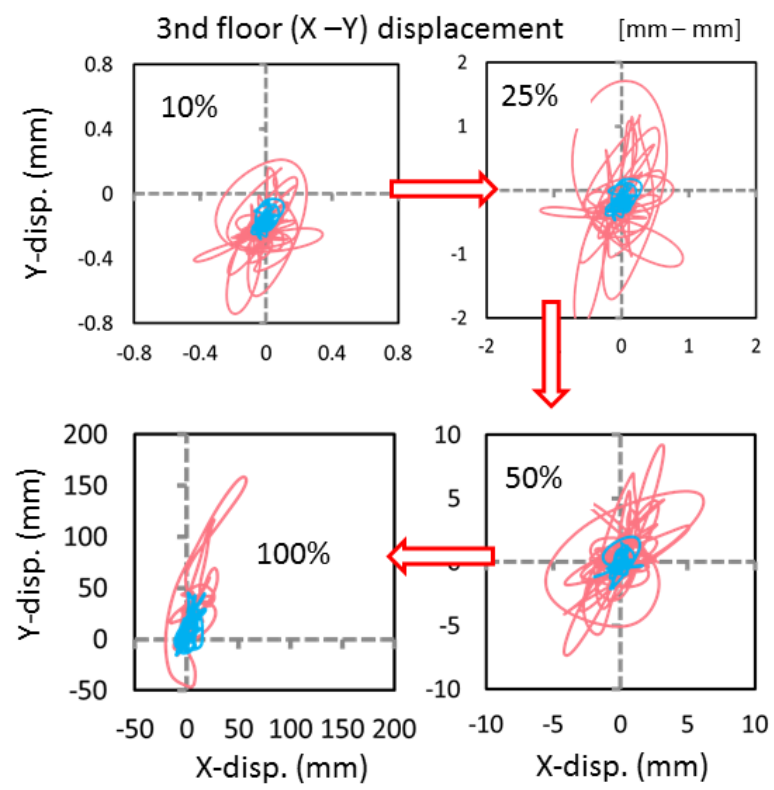

Figure 17: Varying seismic responses according to drying of concrete and curing: blue= wet curing.

Although the seismic responses have much to do with the input wave property, it can be concluded that the stiffness change of the thin structural members caused by drying of concrete has the substantial impact to the overall seismic performances. At the same time, the drying effect extends to the capacity of the members in terms of shear.

\section{SENSITIVITY ANALYSIS ON STEEL CORROSION}

Since the impact of drying shrinkage of concrete may extend to the overall seismic responses, cracking induced by corrosion of reinforcement is thought to cause substantial changes of dynamic responses as well. For investigating sensitivity of corrosive damage, the volumetric expansion of reinforcing bars corresponding to $30 \%$ mass loss of reinforcing bars is numerically produced [17].

Figure 18 shows the comparison of the horizontal drift of the second floor with and without corrosion. When the input amplitude of ground acceleration is small, the drift of the corroded building is large. On the contrary, when the amplitude comes up to $100 \%$, the drift of the non-corroded one is larger than the corroded. Figure 19 shows the drift of each floor in Y-direction when the drift of the top 
floor reaches the maximum. The horizontal displacement response of the first floor in the non-corroded case is almost a half (53\%) of the top one. It is larger than the case of corroded building as 33\%. The failure mode of the first floor's columns turns to the mode of shear from flexure by corrosion, and the load carried by the columns on the first floor is redistributed to other columns.

Corrosion cracks along the main reinforcement may change the mode of failure [18] because the longitudinal cracks deteriorate the bond of reinforcement and the diagonal cracks are arrested. On the other hand, we have a different story about the fatigue life of RC slabs under moving loads [19]. Corrosion along reinforcement reduces the fatigue life no matter how the static capacity is hardly deteriorated. Thus, the impact of corrosion may extend to the whole structural deformability as a macroscopic point of view and the capacity of constituent RC members.
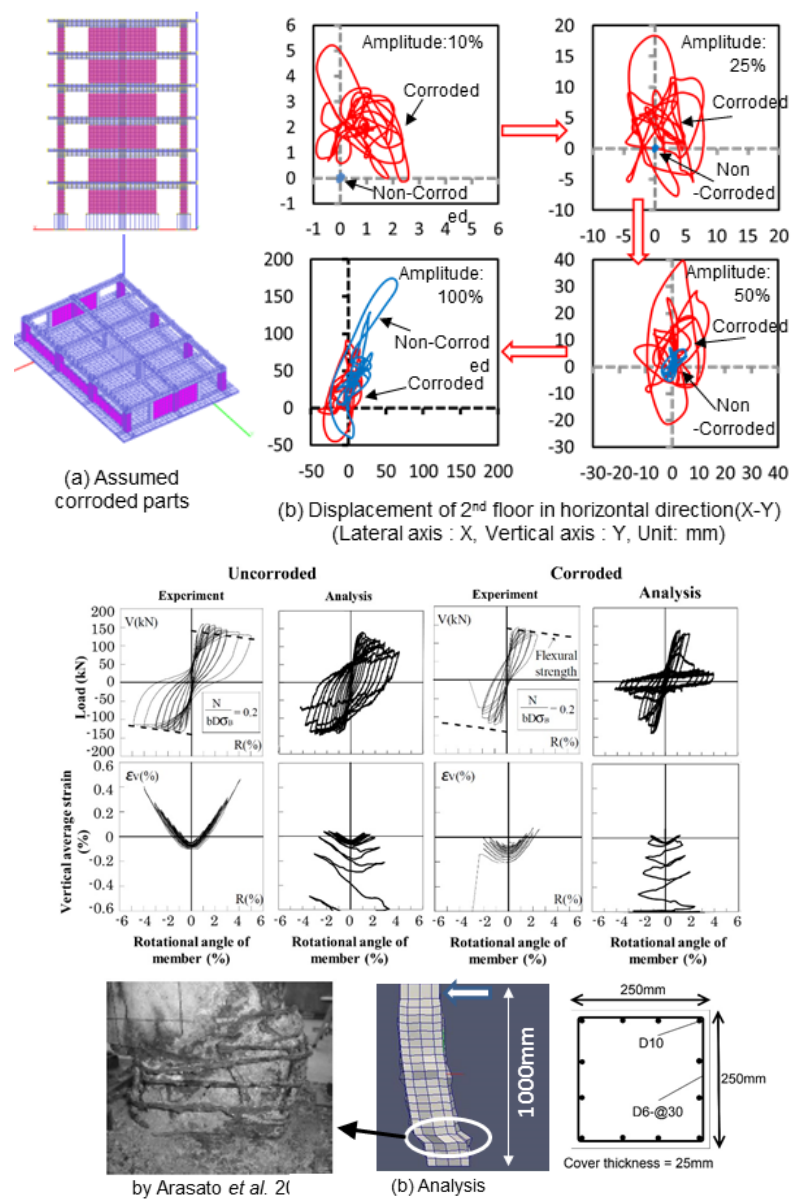

Figure 18: Influence of cracking induced by corrosion of reinforcement on overall seismic responses.

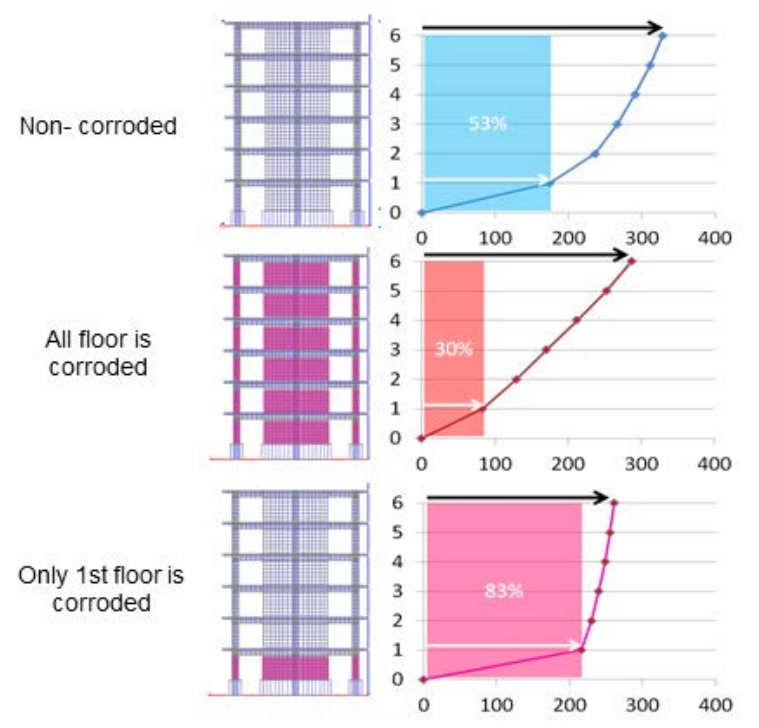

Figure 19: Mode of floor drifts on the horizontal displacement of the top floor.

\section{CONCLUSIONS}

(1) The multi-scale simulation to combine the moisture migration and solid mechanics of concrete can be applied to RC members subjected to combined ambient drying actions and shear forces. The predicted reduction of the shear capacity of beams and slabs is experimentally verified in terms of drying and autogenous shrinkage.

(2) Dynamic responses of the real-scale multistory building were numerically simulated in consideration of the curing process, selfequilibrated stress development and initial cracking. This impact was verified in reference to the large-scale RC mockup dynamically excited on the shaking table.

(3) The sensitivity analyses were conducted on curing of concrete and steel corrosion, and it is concluded that these ambient effects have substantial impact to RC building dynamics. The hygral factor will be associated with size effect of concrete infrastructures and building.

\section{REFERENCES}

[1] Maekawa, K., Ishida, T. and Kishi, T. 2009. Multiscale Modeling of Structural Concrete, Taylor \& Francis.

[2] Chijiwa, N. and Maekawa, K. 2015. Thermo-hygral case-study on full scale $\mathrm{RC}$ building under corrosive environment 
and seismic actions, Journal of Advanced Concrete Technology, 13, 465-478.

[3] Sato, R. and Kawakane, H. 2008. A new concept for the early age shrinkage effect on diagonal cracking strength of reinforced HSC beams, Journal of Advanced Concrete Technology., 6(1), 4567.

[4] Maekawa, K. and Fukuura, N. 2014. Nonlinear modeling of 3D structural reinforced concrete and seismic performance (Chapter 11), Infrastructure Systems for Nuclear Energy, Thomas T. C. Hsu (Ed), John Wiley \& Sons.

[5] Collins, M. P., Bentz, E. C., Quach, P. T. and Proestos, G. T. 2015. The Challenge of predicting the shear strength of very thick slab, Concrete International, ACI, 29-37.

[6] Shioya, T., Iguro, M., Nojiri, Y., Akiyama, H. and Okada, T. 1990. Shear strength of large reinforced concrete beams, SP-118, ACI, 259-280.

[7] Maekawa, K., Pimanmas, A. and Okamura, H. 2004. Nonlinear Mechanics of Reinforced Concrete, E \& FN Spon.

[8] Bazant, Z. P., Sener, S. and Kim, J. 1987. Effect of cracking on drying permeability and diffusivity of concrete, ACI Materials Journal, 351-357.

[9] Asamoto, S., Ishida, T. and Maekawa, K. 2006. Time-dependent constitutive model of solidifying concrete based on thermodynamic state of moisture in fine pores, Journal of Advanced Concrete Technology, 4(2), 301-323.

[10]Yoneda, T., Ishida, T., Maekawa, K., Gebreyouhannes, E. and Mishima, T. 2013. Simulation of early-age cracking due to drying shrinkage based on a multiscale constitutive model, Poromechanics $V$ : ASCE, 579-588.

[11] Gebreyouhannes, E., Yoneda, T., Ishida, T. and Maekawa, K. 2014. Multi-scale based simulation of shear critical reinforced concrete beams subjected to drying, Journal of Advanced Concrete Technology, 12(10), 363-377.

[12]Gebreyouhannes, E. and Maekawa, K. 2011. Numerical simulation on shear capacity and post-peak ductility of reinforced high-strength concrete coupled with autogenous shrinkage, Journal of Advanced Concrete Tech., 9(1), 73-88.

[13] Matsui, S. 1987. The effect of water on the fatigue strength of RC slabs under moving loads, Proc. of the Japan Concrete Institute, 9(2), 627-632.

[14] Maekawa, K., Gebreyouhannes, E., Mishima, T. and An, X. 2006. Threedimensional fatigue simulation of RC slabs under traveling wheel-type loads, Journal of Advanced Concrete Technology, 4(3) 445-457.

[15] Hiratsuka, Y. and Maekawa, K. 2015. Multi-scale and multi-chemo-physics analysis applied to fatigue life assessment of strengthened bridge decks, XIII Int. Conf. on Computational Plasticity. Fundamentals and Applications, 596-607

[16] Matsumori, T., Kabeyazawa, T., Shirai, K. and Igarashi, K. 2008. Shaking table test on a full-scale, six-story R/C building structure, Technical Note of the National Research Institute for Earth Science and Disaster Prevention, No.321.

[17] Toongoenthong, K. and Maekawa, K. 2005. Simulation of coupled corrosive product formation, migration into crack and propagation in reinforced concrete sections, Journal of Advanced Concrete Technology, 3(2), 253-265.

[18] Okada, K., Kobayashi, K. and Miyagawa, T. 1988. Influence of longitudinal cracking due to reinforcement corrosion on characteristics of reinforced concrete members, ACI Structural Journal, 85(2), 134-140.

[19] Maeshima, T., Koda, Y., Tsuchiya, S. and Iwaki, I. 2014. Influence of corrosion of rebars caused by chloride induced determination on fatigue resistance in road bridge deck, Journal of Japan Society of Civil Engineers, Ser.E2, 70(4), 208-225. 